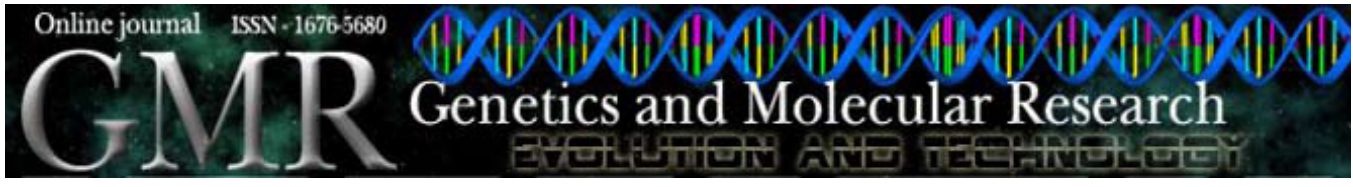

\title{
Lack of association of genetic polymorphisms of angiotensin-converting enzyme gene I/D and glutathione-S-transferase enzyme T1 and $\mathrm{M} 1$ with retinopathy of prematures
}

\author{
M. Yildiz', M. Karkucak ${ }^{2}$, T. Yakut ${ }^{2}$, O. Gorukmez ${ }^{2}$ and A. Ozmen ${ }^{1}$ \\ ${ }^{1}$ Department of Ophthamology, Uludag University, Medical Faculty, \\ Bursa, Turkey \\ ${ }^{2}$ Department of Medical Genetics, Uludag University, Medical Faculty, \\ Bursa, Turkey \\ Corresponding author: M. Yildiz \\ E-mail: meraly@uludag.edu.tr
}

Genet. Mol. Res. 9 (4): 2131-2139 (2010)

Received April 20, 2010

Accepted August 2, 2010

Published October 26, 2010

DOI 10.4238/vol9-4gmr887

\begin{abstract}
One of the most frequently observed causes of blindness in infancy is the pathogenesis known as retinopathy of prematurity (ROP). Angiotensin-converting enzyme (ACE) is a vital enzyme in the renin-angiotensin-aldosterone system; it is involved in the development of cardiovascular system diseases linked to I/D polymorphism of the ACE gene. Glutathione-S-transferase enzyme (GST) is one of the most important regulating components of the antioxidant system; there are indications that certain polymorphisms of GST genes (GSTT1, GSTM1), especially the null genotypes, increase the tendency for oxidative stress diseases. We investigated a possible correlation between ACE gene I/D and GSTT1 and GSTM1 gene polymorphisms in 56 prematures suffering from ROP and a control group composed of 48 prematures without ROP in a hospital in Turkey. PCR was used to detect the ACE I/D, GSTT1 and GSTM1 gene polymorphisms. Genotype was
\end{abstract}


determined based on bands formed on agarose gel electrophoresis. We found no significant differences in genotype frequency of the ACE I/D, GSTT1 and GSTM1 genes between normal subjects and patients with ROP. Our results do not support an association of ACE I/D, GSTT1 and GSTM1 gene polymorphisms with risk for ROP.

Key words: Polymorphism; ACE gene; GSTT1; GSTM1; Retinopathy of prematurity

\section{INTRODUCTION}

Premature retinopathy (ROP), which is one of the most frequently observed causes of blindness in infancy and whose pathogenesis is not clearly defined, is a disease that appears in connection with the abnormal proliferation of the retinal capillaries, and is observed mainly in premature infants with low birth weight (Smith, 2002; Rusai et al., 2008). Currently, its ethiology is not clearly defined. The existence of factors like underdeveloped retinal capillaries, low birth weight, age of pregnancy, hyperoxy connected to oxygen treatment, patient ductus arteriosus, bronchopulmonary dysplasia, apnea that is recurrent and requires mechanical ventilation, hypercapnia and hypocapnia, sepsis, and genetical tendency are considered to play a role in development of the disease (Subhani et al., 2001; Karna et al., 2005; Shah et al., 2005).

Low birth weight and short gestational age have been consistently shown to be associated with ROP. However, the most interesting fact is that in infants with similar clinical characteristics, while the advanced stage of ROP progresses in some, it regresses spontaneously in others. Certain studies have indicated that genetic factors may play a role in this difference (Hutcheson et al., 2005; Shastry and Qu, 2007).

Angiotensin-converting enzyme (ACE), which is a key enzyme in the renin-angiotensin and kinin system, exists in high concentrations on the vascular endothelial cell surface and most of it originates in endothelial tissue. ACE is also observed in kidneys, brain and liver at concentrations lower than in plasma. It plays a major role in adjustment of vascular tone by converting angiotensin- 1 to angiotensin-2, which is a vasoconstrictor agent, and by decomposing bradykinin, which is a vasodilator. At the same time ACE is also related to fibrinolysis, platelet activation and coagulation activation (Hayes et al., 1978; BeneteauBurnat and Baudin, 1991; Vaughan, 1997; Nishimura et al., 1999). The I/D polymorphism, which is the most prevalent polymorphism of the ACE gene, plays a role in the synthesis of ACE, especially the D genotype, and in the development of various cardiovascular diseases (Barceló et al., 2001; Yaggi et al., 2005).

Glutathione-S-transferase (GST) is one of the most important enzymes in the enzymatic antioxidant system. Besides detoxifying exogenous electrophilic xenobiotics, these transferases inactivate endogenous end products formed as secondary metabolites during oxidative stress (Habdous et al., 2004; Hayes et al., 2005; Zhong et al., 2006). Some studies indicate that certain polymorphisms of GST genes (GSTT1, GSTM1) and especially the null genotypes increase the tendency towards diseases related to oxidative stress (Onaran et al., 2000a,b; Strange et al., 2001).

In this study, we investigated the correlation between ROP cases and ACE I/D and GST gene polymorphisms. 


\section{MATERIAL AND METHODS}

\section{Patients}

Our study consisted of 56 patients with ROP and a control group of 48 infants with premature birth who did not show ROP. Our study group included premature babies with either birth weight of $1500 \mathrm{~g}$ or lower, born in the 32nd week or earlier or babies with birth weight between 1500-2000 g or born after the 32nd week with instable clinical status, requiring support in respiration/circulation and declared as being of high risk by the neonatologist/ pediatric specialist monitoring the babies. Cases who met the same criteria but were not diagnosed with retinopathy and had no eye problem were included in the control group.

The babies were submitted to fundus examination using indirect ophthalmoscopy. Before this examination, $2.5 \%$ phenylephrine and $0.5 \%$ tropicamide drops were administered twice at 15-min intervals for pupil dilatation. The first scanning examination was conducted on all babies when their chronological age was 4-6 weeks. When premature retinopathy was not detected, they were re-evaluated in 2-week intervals until the retinal vascularization was complete. When ROP was diagnosed, the babies were examined every week starting from the beginning of the disease until it regressed. For threshold ROP disease treatment, laser photocoagulation under general anesthesia was performed. ROP stages were determined according to the International Premature Retinopathy Classification Committee. A hemogram evaluation was simultaneously performed for all cases in which blood samples were taken for genetic tests and their anemic status was investigated. This study was approved by the Ethics Committee of the Medical School of the University of Uludağ.

\section{Methods}

Blood samples were obtained in EDTA tubes from both patients and controls. DNA was isolated according to the Dr. Zeydanlı (DZ) DNA isolation kit procedure and then stored at $-20^{\circ} \mathrm{C}$ until polymerase chain reaction (PCR) was performed. I/D polymorphism of the ACE gene of DNA samples was determined using the PCR technique. The primers used to determine ACE I/D polymorphism were F: 5'-CTG GAG ACC ACT CCC ATC CTT TCT-3' and R: 5'-GAT GTG GCC ATC ACA TTC GTC AGA T-3', and the D/D genotype insertion area-specific primer: F: 5'-TGG GAC CAC AGC GCC CGC CCG CCA CTA C-3' and R: 5'TCG CCA GCC CTC CCA TGC CCA TAA-3' (Lee and Tsai, 2002). A PCR mixture of $30 \mu \mathrm{L}$ was prepared for ACE gene amplification from the DNA samples. The mixture was prepared to contain $2.5 \mu \mathrm{L} \mathrm{10X} \mathrm{Taq} \mathrm{polymerase} \mathrm{buffer,} 0.5 \mu \mathrm{L} 10 \mathrm{mM}$ dNTP mixture, $2 \mu \mathrm{L} 25 \mathrm{mM}$ $\mathrm{MgCl}_{2}, 1 \mu \mathrm{L} 10$ pmol primary couple, $0.2 \mu \mathrm{L}$ Taq polymerase (Bioron) and $20 \mu \mathrm{L} \mathrm{ddH}_{2} \mathrm{O}$ for each sample. About $3 \mu \mathrm{L}(100 \mathrm{ng})$ of the DNA sample was added to the mixture. To prevent incorrect $\mathrm{D} / \mathrm{D}$ genotyping in samples of $\mathrm{ACE} \mathrm{D} / \mathrm{D}$ genotype, the results were confirmed with a second PCR analysis. PCR conditions were as follows: after the first denaturation for $5 \mathrm{~min}$ at $94^{\circ} \mathrm{C}$, which continued for $1 \mathrm{~min}$ at $94^{\circ} \mathrm{C}$, and then with 35 cycles of annealing for $1 \mathrm{~min}$ at $57^{\circ} \mathrm{C}$ (for verification of $\mathrm{D} / \mathrm{D}$ genotype, at $63^{\circ} \mathrm{C}$ ), and extension for $1 \mathrm{~min}$ at $72^{\circ} \mathrm{C}$, which ended with a final extension for $10 \mathrm{~min}$ at $72^{\circ} \mathrm{C}$.

After PCR, the samples were separated by $2 \%$ agarose gel electrophoresis, stained with ethidium bromide and photographed for the amplification study. As a result of the am- 
plification study, the agarose gel showed an amplification band of 190 bp in samples with the D/D genotype, bands of 490 and $190 \mathrm{bp}$ in samples with the I/D genotype and a band of $490 \mathrm{bp}$ in samples with the I/I genotype (Figure 1). In the second PCR analysis conducted for $\mathrm{D} / \mathrm{D}$ confirmation, an amplification band of $335 \mathrm{bp}$ was observed with samples that had the insertion band.

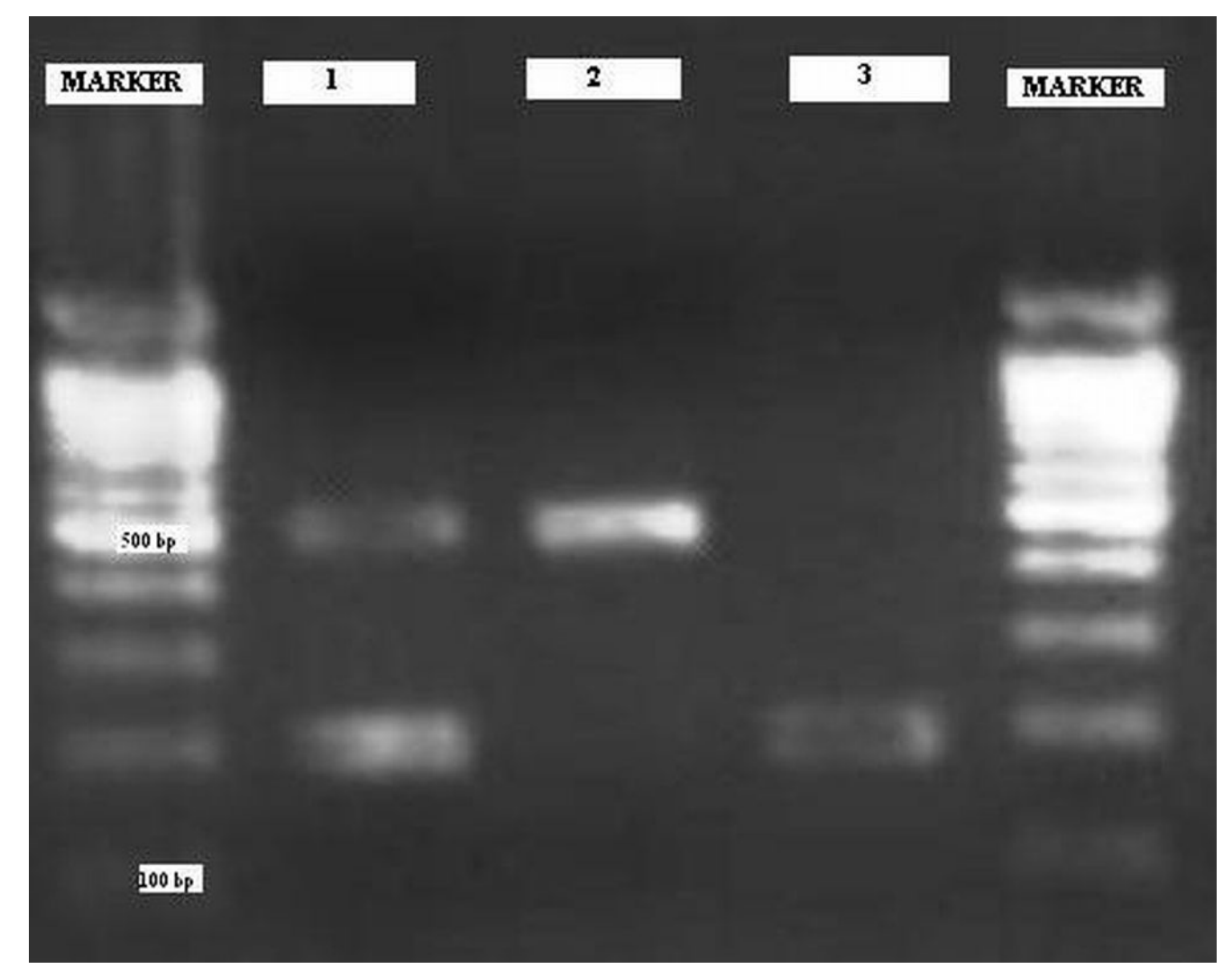

Figure 1. Detection of ACE gene I/D polymorphism by polymerase chain reaction. Lane MARKER = a 100-bp DNA ladder. Lane 1 = I/D genotype (490/190 bp); lane $2=\mathrm{I} / \mathrm{I}$ genotype $(490 / 490 \mathrm{bp})$; lane 3 = D/D genotype (190/190 bp).

The multiplex PCR method was used to determine GSTM1 and GSTT1 polymorphisms in the isolated DNAs. For the GSTT1 polymorphism, forward 5'-TTCCTTACTGGTCCTCACA TCTC-3' and reverse 5'-TCACCGGATCATGGCCAGCA-3' primers were used. For the GSTM1 polymorphism, forward 5'-GAACTCCCTGAAAAGCTAAAGC-3' and reverse 5'-GTTGGGCTCAAATATACGGTGG-3' primers were used. Albumin forward 5'-GCCCTCTGC TAACAAGTCCTAC-3' and reverse 5'-GCCCTAAAAAGAAAATCCCCAATC-3' primers were used as internal controls (Abbas et al., 2004). Albumin (350 bp), GSTM1 (219 bp) and GSTT1 (459 bp) PCR products were formed. PCR conditions required denaturation for $5 \mathrm{~min}$ at $94^{\circ} \mathrm{C}$ and then 35 cycles as follows: $1 \mathrm{~min}$ at $94^{\circ} \mathrm{C}$ (denaturation), $1 \mathrm{~min}$ at $58^{\circ} \mathrm{C}$ (annealing), 1 min at $72^{\circ} \mathrm{C}$ (elongation) and finally $10 \mathrm{~min}$ at $72^{\circ} \mathrm{C}$ (final elongation). Genotypes were 
determined by migration of the products on agarose gel with $2 \%$ ethidium bromide (Figure 2).

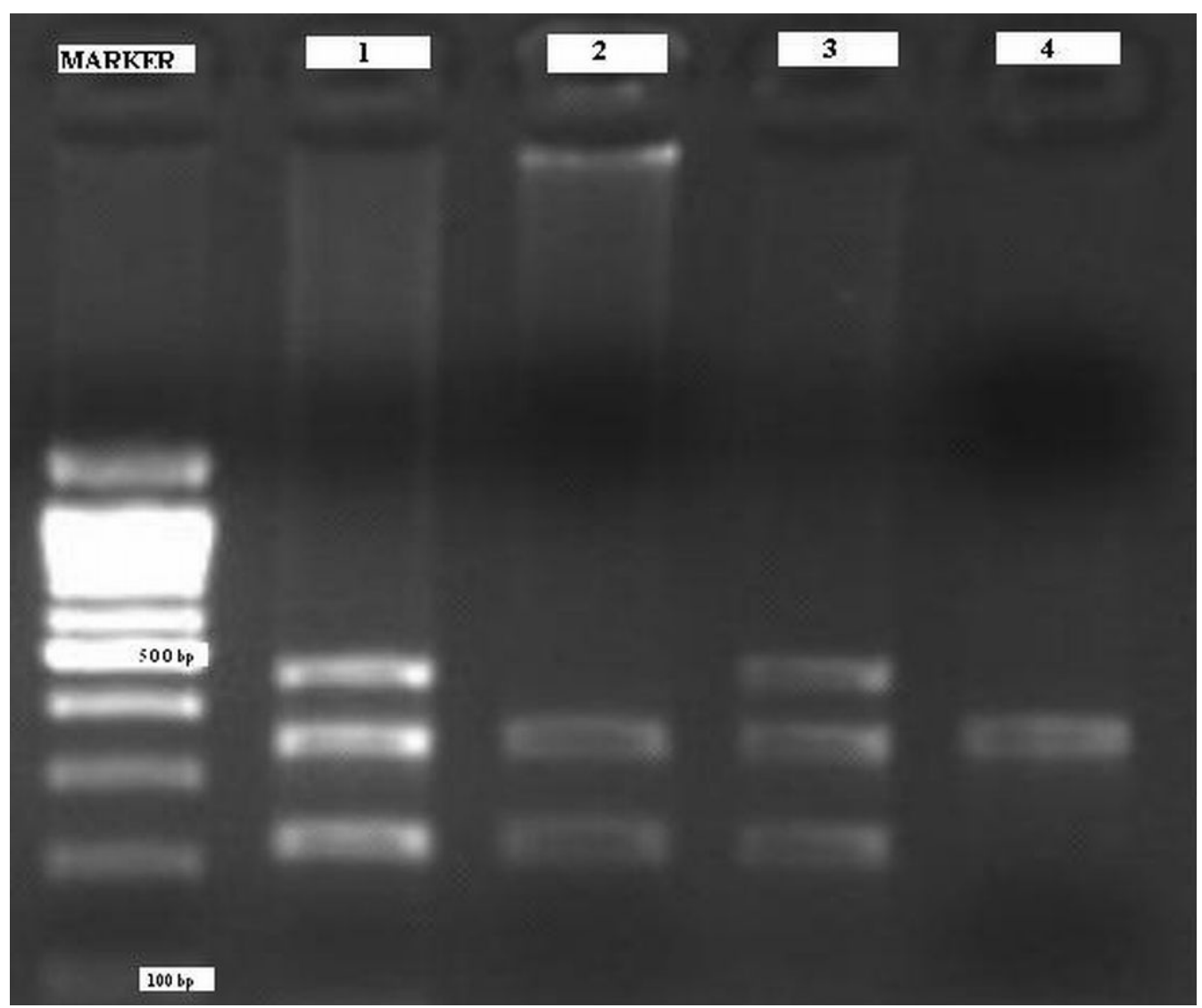

Figure 2. A representative multiplex polymerase chain reaction (PCR) analysis of GST polymorphisms. Albumin (350 bp), GSTT1 (459 bp) and GSTM1 (219 bp) genes. PCR products resolved by agarose gel electrophoresis. Lane MARKER = a 100-bp DNA ladder. Lanes 1 and $3=$ both GSTT1 and GSTM1 present genotypes; lane $2=$ GSTM1 present genotype and GSTT1 null genotype; lane 4 = both GSTT1 and GSTM1 null genotypes.

\section{Statistical analysis}

Data are reported as means \pm standard deviation. The SPSS 13.0 program was used for the analysis. The chi-square $\left(\chi^{2}\right)$ test was used to compare genotypes. A value of $\mathrm{P}<0.05$ was accepted as indicating a statistically significant difference.

\section{RESULTS}

In this study, among the 56 cases in the patient group ( 29 males and 27 females), the birth weight was $1321 \pm 318 \mathrm{~g}$, and among the 48 cases in the control group (18 males and 30 females), the birth weight was $1469 \pm 287 \mathrm{~g}$ on average (Table 1). 
Table 1. Clinical characteristics of ROP patients and controls.

\begin{tabular}{lcr}
\hline & ROP patients $(\mathrm{N}=56)$ & Control group $(\mathrm{N}=48)$ \\
\hline Males/Females (N) & $29 / 27$ & $18 / 30$ \\
Birth weight (grams) & $1321 \pm 318$ & $1469 \pm 287$ \\
Gestational age at birth (weeks) & $29.71 \pm 1.4$ & $31 \pm 1.4$ \\
\hline
\end{tabular}

Data are reported as means $\pm \mathrm{SD}$.

No significant differences in allele and genotype frequencies for any polymorphism were observed between ROP patients and controls, although the D allele was less frequent in ROP patients $(\mathrm{P}>0.05)$. In the patient group, the frequencies of the I and $\mathrm{D}$ alleles were 38 and $62 \%$, respectively, and in the control group they were 32 and $68 \%$, respectively (Table 2).

\begin{tabular}{|c|c|c|c|}
\hline & ROP patients $(\mathrm{N}=56)$ & Control group $(\mathrm{N}=48)$ & $\mathrm{P}$ \\
\hline I/I Genotype & $10(18 \%)$ & $4(8 \%)$ & $>0.05$ \\
\hline I/D Genotype & $23(41 \%)$ & $23(48 \%)$ & \\
\hline D/D Genotype & $23(41 \%)$ & $21(44 \%)$ & \\
\hline Prevalence of I allele (\%) & $38 \%$ & $32 \%$ & $>0.05$ \\
\hline Prevalence of D allele (\%) & $62 \%$ & $68 \%$ & \\
\hline
\end{tabular}

Data are reported as number with percent in parentheses.

Table 3 shows the distribution of GSTM1 and GSTT1 polymorphisms among the patients and controls. While the number of patients carrying the GSTT1 null genotype was determined to be 18 (32\%) among ROP patients, this was identified to be $8(17 \%)$ among the control group. When the groups were compared in terms of GSTM1 polymorphism, the null genotype among the patient group was $29(51 \%)$ while it was $25(52 \%)$ in the control group. When the groups were compared in terms of GSTT1 and GSTM1 genotypes, no statistical significance was determined $(\mathrm{P}>0.05)$.

\begin{tabular}{llrrr}
\multicolumn{4}{l}{ Table 3. GSTM1, GSTT1 and GSTP1 polymorphism rates among ROP patients and controls. } & \\
\hline Genes & Genotype & ROP patients $(\mathrm{N}=56)$ & Control group $(\mathrm{N}=48)$ & P \\
\hline GSTT1 & Null & $18(32 \%)$ & $8(17 \%)$ & $>0.05$ \\
& Present & $38(68 \%)$ & $40(83 \%)$ & $>0.05$ \\
GSTM1 & Null & $29(51 \%)$ & $25(52 \%)$ & $23(48 \%)$ \\
& Present & $27(49 \%)$ & & \\
\hline
\end{tabular}

Data are reported as number with percent in parentheses.

\section{DISCUSSION}

While currently the ROP etiology is not well defined, studies conducted with large numbers of individuals report that factors like low birth weight and short gestational period are involved (Bossi and Koerner, 1995; Haider et al., 2002). Among infants with similar clinical characteristics, it was noted that while the advanced stage of ROP progresses in some, it regresses spontaneously in others. Genetic factors are reported to have some influence on the progression of the advanced stage of ROP among infants of white skin color when compared with infants with black skin color (Ng et al., 1988; Hutcheson et al., 2005; Shastry and Qu, 2007).

In our study, we investigated whether GST1, GSTM1 and ACE I/D gene polymor- 
phisms have an impact on ROP development risk. We showed that there is no correlation in terms of polymorphism when the patient group is compared with the control group.

In the study conducted by Haider et al. (2002), regarding the ACE I/D polymorphism in ROP patients, a significance was determined in terms of the I/I genotype, and a higher rate of the I/I genotype was detected in the patient group. On the other hand, in our study, when patient and control groups are compared, the rate of $\mathrm{I} / \mathrm{D}$ and $\mathrm{D} / \mathrm{D}$ genotypes was determined to be close, and even though the I/I genotype was determined to be higher in the patient group when compared to the control group, no significant difference was observed (Table 2) $(\mathrm{P}>0.05)$.

Glutathione S-transferases can work as endogenous antioxidants to protect cells from oxidative stress. It is observed that the GSTT1 and GSTM1 null genotypes cause a decrease in enzyme activity and the oxidative stress inactivation is reduced especially in people with the GSTM1 null genotype (Van der Hel et al., 2003; Uzunoğlu et al., 2006). As far as we know, up to this date, there has been no study investigating ROP progress with GSTT1 and GSTM1 polymorphisms. We also analyzed the correlation of the GSTT1 and GSTM1 null genotypes as well as ACE polymorphism among the patient group compared to the control group. While the GSTM1 null genotype rate among patients and controls is similar (51vs 52\%) it is observed that the GSTT1 null genotype rate is higher among patients (32 vs 17\%) (Table 3). When this was analyzed statistically, no significance was determined $(\mathrm{P}>0.05)$.

There are certain genetic studies that may shed light on the pathogenesis related to the beginning and progress of this complex disease. In a study conducted by Shastry et al. (1997), a relationship was discovered among patients with advanced stage of ROP and the missense mutation of the Norrire disease gene. However, in another study, Haider et al. $(2000,2001)$ did not present an association with the missense mutation of the Norrire disease gene at the beginning or advanced stage. Besides, research was conducted on polymorphisms of genes of various factors including vascular endothelial growth factor (VEGF), insulin-like growth factor I receptor (IGF-IR), endothelial nitric oxide synthase (eNOS), and angiopoietin 2, which may play a role in the progress of ROP disease. In one study, Rusai et al. (2008) analyzed the eNOS gene T-786C and the 27-bp repeat gene polymorphisms and asserted that the 27-bp repeat may play a role in the advanced level of ROP progress. No correlation was found in studies conducted with VEGF, IGF-IR and angiopoietin 2 gene polymorphisms. Bányász et al. (2006), Kwinta et al. (2008), and Shastry (2009) have not identified any correlation between ROP progress and VEGF polymorphisms. Again, in studies conducted by Balogh et al. (2006) and Shastry (2007) no correlation was identified between IGF-IR gene G(+3174)A polymorphism and a tendency for the progress of the disease.

To conclude, no correlation was identified between patient and control groups, in terms of the ACE gene and I/D polymorphism as well as the GSTM1 and GSTT1 polymorphisms. Studies must be conducted on larger groups of cases to analyze the GSTP1 (Ile/Val) and other cytokine gene polymorphisms that might have a role in the etiopathogenesis of ROP.

\section{REFERENCES}

Abbas A, Delvinquiere K, Lechevrel M, Lebailly P, et al. (2004). GSTM1, GSTT1, GSTP1 and CYP1A1 genetic polymorphisms and susceptibility to esophageal cancer in a French population: different pattern of squamous cell carcinoma and adenocarcinoma. World J. Gastroenterol. 10: 3389-3393.

Balogh A, Derzbach L, Vannay A and Vásárhelyi B (2006). Lack of association between insulin-like growth factor I 
receptor G (+3174)A polymorphism and retinopathy of prematurity. Graefes Arch. Clin. Exp. Ophthalmol. 244: 1035-1038.

Bányász I, Bokodi G, Vannay A, Szebeni B, et al. (2006). Genetic polymorphisms of vascular endothelial growth factor and angiopoietin 2 in retinopathy of prematurity. Curr. Eye Res. 31: 685-690.

Barceló A, Elorza MA, Barbé F, Santos C, et al. (2001). Angiotensin converting enzyme in patients with sleep apnoea syndrome: plasma activity and gene polymorphisms. Eur. Respir. J. 17: 728-732.

Beneteau-Burnat B and Baudin B (1991). Angiotensin-converting enzyme: clinical applications and laboratory investigations on serum and other biological fluids. Crit. Rev. Clin. Lab. Sci. 28: 337-356.

Bossi E and Koerner F (1995). Retinopathy of prematurity. Intensive Care Med. 21: 241-246.

Habdous M, Siest G, Herbeth B, Vincent-Viry M, et al. (2004). Glutathione S-transferases genetic polymorphisms and human diseases: overview of epidemiological studies. Ann. Biol. Clin. 62: 15-24.

Haider MZ, Devarajan LV, Al-Essa M, Srivastva BS, et al. (2000). Missense mutations in norrie disease gene are not associated with advanced stages of retinopathy of prematurity in Kuwaiti arabs. Biol. Neonate 77: 88-91.

Haider MZ, Devarajan LV, Al-Essa M, Srivastva BS, et al. (2001). Retinopathy of prematurity: mutations in the Norrie disease gene and the risk of progression to advanced stages. Pediatr. Int. 43: 120-123.

Haider MZ, Devarajan LV, Al-Essa M and Kumar H (2002). Angiotensin-converting enzyme gene insertion/deletion polymorphism in Kuwaiti children with retinopathy of prematurity. Biol. Neonate 82: 84-88.

Hayes JD, Flanagan JU and Jowsey IR (2005). Glutathione transferases. Annu. Rev. Pharmacol. Toxicol. 45: 51-88.

Hayes LW, Goguen CA, Ching SF and Slakey LL (1978). Angiotensin-converting enzyme: accumulation in medium from cultured endothelial cells. Biochem. Biophys. Res. Commun. 82: 1147-1153.

Hutcheson KA, Paluru PC, Bernstein SL, Koh J, et al. (2005). Norrie disease gene sequence variants in an ethnically diverse population with retinopathy of prematurity. Mol. Vis. 11: 501-508.

Karna P, Muttineni J, Angell L and Karmaus W (2005). Retinopathy of prematurity and risk factors: a prospective cohort study. BMC Pediatr. 5: 18.

Kwinta P, Bik-Multanowski M, Mitkowska Z, Tomasik T, et al. (2008). The clinical role of vascular endothelial growth factor (VEGF) system in the pathogenesis of retinopathy of prematurity. Graefes Arch. Clin. Exp. Ophthalmol. 246: $1467-1475$.

Lee YJ and Tsai JC (2002). ACE gene insertion/deletion polymorphism associated with 1998 World Health Organization definition of metabolic syndrome in Chinese type 2 diabetic patients. Diabetes Care 25: 1002-1008.

$\mathrm{Ng}$ YK, Fielder AR, Shaw DE and Levene MI (1988). Epidemiology of retinopathy of prematurity. Lancet 2: 1235-1238.

Nishimura H, Tsuji H, Masuda H, Kasahara T, et al. (1999). The effects of angiotensin metabolites on the regulation of coagulation and fibrinolysis in cultured rat aortic endothelial cells. Thromb. Haemost. 82: 1516-1521.

Onaran I, Ozaydin A, Ozdas SB and Ulutin T (2000a). Inhibition of platelet function by GSTM1-null human peripheral lymphocytes exposed to benzo(a)pyrene-induced challenge. Cell Biol. Toxicol. 16: 313-323.

Onaran I, Ozaydin A, Akbas F, Gultepe M, et al. (2000b). Are individuals with glutathione S-transferase GSTT1 null genotype more susceptible to in vitro oxidative damage? J. Toxicol. Environ. Health A 59: 15-26.

Rusai K, Vannay A, Szebeni B, Borgulya G, et al. (2008). Endothelial nitric oxide synthase gene T-786C and 27-bp repeat gene polymorphisms in retinopathy of prematurity. Mol. Vis. 14: 286-290.

Shah VA, Yeo CL, Ling YL and Ho LY (2005). Incidence, risk factors of retinopathy of prematurity among very low birth weight infants in Singapore. Ann. Acad. Med. Singapore 34: 169-178.

Shastry BS (2007). Assessment of the contribution of insulin-like growth factor I receptor $3174 \mathrm{G} \rightarrow$ A polymorphism to the progression of advanced retinopathy of prematurity. Eur. J. Ophthalmol. 17: 950-953.

Shastry BS (2009). Lack of association of VEGF $(-2578 \mathrm{C} \rightarrow \mathrm{A})$ and ANG $2(-35 \mathrm{G} \rightarrow \mathrm{C})$ gene polymorphisms with the progression of retinopathy of prematurity. Graefes Arch. Clin. Exp. Ophthalmol. 247: 859-860.

Shastry BS and Qu X (2007). Lack of association of the VEGF gene promoter (-634 G $\rightarrow \mathrm{C}$ and $-460 \mathrm{C} \rightarrow \mathrm{T}$ ) polymorphism and the risk of advanced retinopathy of prematurity. Graefes Arch. Clin. Exp. Ophthalmol. 245: 741-743.

Shastry BS, Pendergast SD, Hartzer MK, Liu X, et al. (1997). Identification of missense mutations in the Norrie disease gene associated with advanced retinopathy of prematurity. Arch. Ophthalmol. 115: 651-655.

Smith LE (2002). Pathogenesis of retinopathy of prematurity. Acta Paediatr. 91: 26-28.

Strange RC, Spiteri MA, Ramachandran S and Fryer AA (2001). Glutathione-S-transferase family of enzymes. Mutat. Res. 482: 21-26.

Subhani M, Combs A, Weber P, Gerontis C, et al. (2001). Screening guidelines for retinopathy of prematurity: the need for revision in extremely low birth weight infants. Pediatrics 107: 656-659.

Uzunoğlu S, Acar H, Okudan N, Gökbel H, et al. (2006). Evaluation of the association between null genotypes of glutathione-S-transferases and Behcet's disease. Arch. Dermatol. Res. 297: 289-293.

Genetics and Molecular Research 9 (4): 2131-2139 (2010)

CFUNPEC-RP www.funpecrp.com.br 
Van der Hel OL, Peeters PH, Hein DW, Doll MA, et al. (2003). NAT2 slow acetylation and GSTM1 null genotypes may increase postmenopausal breast cancer risk in long-term smoking women. Pharmacogenetics 13: 399-407.

Vaughan DE (1997). The renin-angiotensin system and fibrinolysis. Am. J. Cardiol. 79: 12-16.

Yaggi HK, Concato J, Kernan WN, Lichtman JH, et al. (2005). Obstructive sleep apnea as a risk factor for stroke and death. N. Engl. J. Med. 353: 2034-2041.

Zhong SL, Zhou SF, Chen X, Chan SY, et al. (2006). Relationship between genotype and enzyme activity of glutathione S-transferases M1 and P1 in Chinese. Eur. J. Pharm. Sci. 28: 77-85. 